\title{
Current Gaps and Needs for Increasing Access to Healthcare for People with Chagas Disease in the USA
}

\author{
Colin J. Forsyth ${ }^{1}$ - Paula Stigler Granados ${ }^{2} \cdot$ Gerardo J. Pacheco ${ }^{3}$ • José A. Betancourt ${ }^{2}$ • Sheba K. Meymandi ${ }^{1}$
}

Published online: 24 January 2019

(C) The Author(s) 2019

\begin{abstract}
Purpose of Review In the USA, fewer than $1 \%$ of people with Chagas disease (CD) are diagnosed and treated. Patients and physicians confront significant barriers to initiating testing and treatment, which are not systematically available in the US health care system. What are these barriers and how can they be overcome? We discuss the broader challenges and state-level dynamics of CD in several of the US states with the highest burdened populations.

Recent Findings The principal challenges for expanding access to testing and treatment include confusion surrounding testing procedures, limitations in available drugs and diagnostic tools, gaps in surveillance and epidemiological knowledge, low patient awareness, and, particularly, low awareness among providers. States have key differences concerning health care access, transmission dynamics, and programmatic resources. Local initiatives in Texas and California are discussed.

Summary Reducing the burden of CD will require improvement of diagnostic capacity and treatment guidelines, significant strengthening of provider awareness, greater understanding of transmission dynamics, and provision of accessible health care to the diverse population at risk.
\end{abstract}

Keywords Chagas disease $\cdot$ Health care disparities $\cdot$ Vector-borne diseases $\cdot$ Neglected tropical diseases $\cdot$ Trypanosoma cruzi

\section{Introduction}

Chagas disease (CD), one of the world's most neglected health conditions, is a leading cause of heart disease in the Americas, creating a greater burden in disability-adjusted life-years (DALYs) than any other parasitic infection, including malaria and Zika [1]. Caused by the protozoan Trypanosoma cruzi, $\mathrm{CD}$ affects over six million people across the globe, over $90 \%$ of whom are in Latin America, leading to over 7500 premature deaths annually. Additionally, CD exacts an immense global economic toll of 8 billion USD annually [2]. Despite

This article is part of the Topical Collection on Chagas

Paula Stigler Granados

psgranados@txstate.edu

1 Center of Excellence for Chagas Disease at Olive View-UCLA Medical Center, Sylmar, CA, USA

2 College of Health Professions, School of Health Administration, Texas State University, 601 University Dr., Encino Hall, \#274, San Marcos, TX, USA

3 UTHealth School of Public Health, San Antonio, TX, USA these economic and public health implications, there has been little investment in research and development for $\mathrm{CD}$, and the vast majority of people with the infection are undiagnosed and untreated.

$\mathrm{CD}$ is most commonly transmitted by blood-sucking triatomine insects, known as kissing bugs in the USA and by various names in Latin America (chinche besucona, vinchuca, barbeiro, pito, chipo). Congenital transmission occurs in roughly $5 \%$ of births to infected mothers in endemic areas and $2.7 \%$ in non-endemic settings [3]. Blood transfusion, organ transplantation, laboratory accidents, needle sharing, and oral transmission (through consumption of contaminated food and drinks) are additional transmission routes. $\mathrm{CD}$ has an acute phase following infection, which usually goes unrecognized because it is either asymptomatic or resembles common viral illnesses. This is followed by a chronic asymptomatic phase; however, typically decades after infection, $30-40 \%$ of those infected will develop life-threatening cardiac, gastrointestinal, or neurological complications.

In the USA, modeled estimates suggest there are between 326,000 and 347,000 Latin American-born individuals with T. cruzi infections. Additionally, autochthonous infections, which can potentially be transmitted by 11 different species 
of US triatomines [4], are increasingly being documented [5-7]. Transmission rates are thought to be lower in the USA compared to Latin America, due to different housing conditions, lower levels of vector domiciliation, and different vector feeding behaviors $[4,8]$. However, the exact incidence and prevalence of $\mathrm{CD}$ caused by local triatomines remain unknown. Vertical transmission is another important pathway; estimates suggest 63-315 cases of congenital infection occur annually [9], but thus far there is a marked absence of surveillance data.

In the USA, less than $1 \%$ of people with CD receive a clinical diagnosis, and an even smaller fraction receives antiparasitic treatment [10]. Studies suggest similarly low rates of coverage in Mexico and Colombia [11, 12], while in Europe, less than $10 \%$ of people with CD are officially diagnosed [13]. A diverse web of barriers perpetuates the global neglect of the disease, including limitations in diagnostic and therapeutic tools, the genetic diversity of the parasite, and the social vulnerability of many people with the disease. In the USA, exclusion of many immigrants from health care, very low awareness of the disease in both health care providers and the at-risk populations, and immense gaps in screening coverage add to these challenges $[9,10]$.

Currently, there are only two drugs effective against T. cruzi infection: benznidazole and nifurtimox. Both are effective at eliminating the parasite and have high cure rates for congenital, acute, and recent chronic cases [14-16]. Although efficacy is difficult to measure in chronically infected adults, studies have shown that treatment can reduce morbidity and mortality for this patient population [17-19], and most guidelines therefore recommend offering treatment. Additionally, antitrypanosomal treatment of infected women of childbearing age has been shown to prevent future congenital transmission $[20,21]$. The BENEFIT trial did not demonstrate a significant impact of treatment in patients with moderate to severe cardiomyopathy suggesting that it is critical to treat patients early, before the onset of cardiac involvement $[22,23]$.

\section{Access to Drugs and Diagnostics}

Until recently, benznidazole and nifurtimox were only available from the US Centers for Disease Control and Prevention (CDC) through an investigational new drug protocol. The advantage to this was that the $\mathrm{CDC}$ served as a gatekeeper for diagnosis and treatment. They offered assistance with confirmatory diagnosis and provided medications at no cost to the patient. However, the bureaucratic processes necessitated by the protocol created challenges for providers [10]. Many physicians reported reluctance or inability to sign on to investigational protocols due to concerns over liability for their practices or institutions. In August 2017, benznidazole was approved by the U.S. Food and Drug Administration for use in children aged 2-12 years, and the drug was launched in
May 2018 [24]. Although only $1 \%$ of patients with CD in the USA fall within this age range, clinicians can prescribe benznidazole off-label for other age groups. Providers can order benznidazole through an online pharmacy at www. benznidazoletablets.com, while nifurtimox is available through the CDC's investigational protocol. Making benznidazole commercially available in the USA and removing the bureaucratic process of the investigational protocol should increase physicians' capacity and willingness to treat. The drug is also available as a low or no-cost option to patients, alleviating financial barriers for uninsured or underinsured patients.

Although benznidazole is the preferred treatment for CD, having two antitrypanosomal drugs available is important because roughly $20-25 \%$ of patients are compelled to discontinue treatment due to side effects $[25,26]$. In studies, US patients treated with benznidazole and nifurtimox experienced a mean of 3.5 and 8.2 adverse reactions, respectively [26, 27]. Patients who had more side effects per 30 days or who experienced moderate to severe side effects were more likely to discontinue treatment than were patients who did not have these experiences. Treatment is currently not recommended for patients over the age of 50 years (although patients up to age 60 years may be considered on a case-by-case basis) because of the potential for side effects and uncertain efficacy $[28,29]$.

The availability of adequate diagnostic tools and protocols for CD diagnosis in the USA is another key concern [30]. Currently, only four CD assays have FDA clearance for clinical use; only one is a rapid test. No test has sufficiently high sensitivity and specificity to act as a stand-alone test, so diagnosis requires confirmatory testing with a second assay and, in case of discordance, a third. Complicating matters further, the available assays were largely developed with South American T. cruzi strains that are different from those affecting most of the US population with $\mathrm{CD}$. The accuracies of the four available tests in a US clinical population are unknown. While the $\mathrm{CDC}$ has played a pivotal role in ensuring rigorous diagnostic confirmation, wider scaling-up of CD testing throughout the US health system may necessitate decentralization. Other key needs are developing an evidence-based diagnostic algorithm for US clinicians and identifying or developing new point-ofcare tests with sufficient specificity and sensitivity for the whole spectrum of patients and T. cruzi strains within the USA. This process may also involve obtaining regulatory approval for one or more Chagas tests not currently available in the USA.

Due to limitations in the current diagnostics, it is often confusing for physicians in the USA to decide which assays to choose for their patients. There have been several anecdotal reports of physicians telling their patients not to worry about a positive screening from a blood donation due to frequent false positives (over $75 \%$ of screened positives are eventually 
confirmed negative) [31]. Poor diagnostics can diminish risk perception, creating additional barriers for patients and physicians.

\section{Cultural Considerations}

Cultural differences between providers and patients have a crucial impact. Many CD patients speak English as a second language, whereas health care workers may not speak Spanish (or may not speak it well enough to discuss the complexities associated with a CD diagnosis). Language differences in combination with low provider familiarity with CD [32-34] can sometimes pose an insurmountable barrier to initiating treatment. Latin American patients may have different expectations about treatment goals than do providers trained within the US health care system. Importantly, "Latin Americans" are an incredibly heterogeneous group in terms of ethnicity, social class, nationality, and other factors, meaning there is not a "one-size-fits all" communication strategy. Many Latin American-born individuals prefer self-treatment with alternative or traditional remedies, although this has not posed a barrier to accepting biomedical treatment for CD among patients in Los Angeles [35]. Even in the USA, there are large regional differences in how Latino populations may perceive risk and choose to address CD. For example, in Texas, large populations of US-born Latinos living along the border cross into Mexico frequently for shopping, medical care, and family visits. There has been at least one case of a US citizen choosing to access testing and treatment for $\mathrm{CD}$ in Mexico as a cheaper and better alternative to treatment in Texas [36].

Patients often describe a diagnosis of $\mathrm{CD}$ as upsetting and frightening [37-39]. Once diagnosed, they may feel ongoing anxiety about the impact of the disease. Depression has been associated with $\mathrm{CD}$, particularly in patients who experience complications [40]. Some may feel it is better "not to know" if they have $\mathrm{CD}$, since this knowledge would only be a source of worry, and courses of action to manage the disease are limited [41]. Because CD is often associated with rural poverty, patients may feel a diagnosis is stigmatizing, which could limit their comfort with getting tested or subsequently seeking care. The fact that CD is rarely discussed in news media (and even then frequently and inaccurately portrayed as an exotic disease brought by immigrants) only adds to the feelings of isolation diagnosed patients experience.

\section{State-Level Comparisons}

Access to treatment for CD in the USA is impacted by specific epidemiological, social, and political contexts, in addition to state and local health policies and health care capabilities. Table 1 compares epidemiological and public health indicators for California, Texas, Florida, and New York, the four states with the highest estimated burdens of the disease [42]. Roughly $60 \%$ of people with CD live within one of these states, which should be prioritized for implementation of new public health and surveillance programs. Because of ecological, geographic, and historical factors, Latinos might have a higher risk of $\mathrm{CD}$ and would therefore benefit from screening programs. Each state in Table 1 has a large population of Latin American-born residents. Moreover, three states are habitats for local triatomines, led by Texas, where at least eight species capable of transmitting T. cruzi can be found [4]. Texas is also the only state where CD is reportable [50], although more patients were treated with benznidazole in California in recent years than in the other three combined [46]. The Medicaid expansion of 2014 is a key health care access indicator, because it permitted greater insurance coverage for immigrants and other socially vulnerable populations, including rural residents, who might be at risk for $\mathrm{CD}$. While California and New York accepted the Medicaid expansion, it was rejected by Texas and Florida. In the latter two states, rates of uninsured are nearly double when compared to California or New York. In fact, Texas has the highest uninsured population in the country at $17 \%$ [51]. Nonetheless, in the present political climate, immigrants (both legal and undocumented, from Florida to California) have expressed increasing hesitation to sign up for publicly funded health care programs for fear they or their close relatives may suffer negative consequences [52].

There has been limited on-the-ground epidemiological research to help further quantify and characterize the burden of $\mathrm{CD}$ in the four states, largely because systematic screening of $\mathrm{CD}$ does not routinely occur outside of blood donation and organ transplantation settings. Recognizing the importance of $\mathrm{CD}$ and the lack of understanding of the US prevalence, in 2015, the CDC funded three separate projects to address awareness. One project focused on access to treatment for immigrant populations in New York. The other projects were in Texas, one focusing on health care provider awareness and the other on congenital CD. As a result, Texas created a statewide taskforce to raise awareness and conduct outreach with physicians and health networks. The Texas Chagas Task Force has identified key barriers to accessing appropriate diagnosis and treatment for both physicians and patients [53]. Concurrently, mandatory reporting of CD in Texas has markedly improved collaboration between epidemiologists and healthcare providers, strengthening their efforts to raise awareness of CD. Meanwhile, in Los Angeles, the Center of Excellence for Chagas Disease at Olive View-UCLA Medical Center (CECD) has been conducting communitybased screening for CD and treating patients since 2007 . Below, we discuss state-level public health and health care access dynamics for $\mathrm{CD}$, focusing on Texas and California based on the experience of the Texas Chagas Task Force and the CECD. 
Table 1 Public health indicators for Chagas disease in the highest-prevalence US states

\begin{tabular}{|c|c|c|c|c|}
\hline & California & Texas & Florida & New York \\
\hline Estimated burden of CD, (US ranking) [42] & $70,860(1)$ & $36,977(2)$ & $18,096(3)$ & $17,403(4)$ \\
\hline $\begin{array}{l}\text { Latino population, millions Pew Research } \\
\text { Center }[43,44]\end{array}$ & 15.2 & 10.7 & 5.0 & 3.7 \\
\hline As $\%$ of state pop. & 39.0 & 38.2 & 24.0 & 19.0 \\
\hline$\%$ foreign born & 36.0 & 30.0 & 48.0 & 39.0 \\
\hline Chagas reportable? & No & Yes & No & No \\
\hline Local vectors [4] & $\begin{array}{l}\text { T. leticularia } \\
\text { T. rubida } \\
\text { T. protracta } \\
\text { P. hirsuta }\end{array}$ & $\begin{array}{l}\text { T. leticularia } \\
\text { T. sanguisuga } \\
\text { T. rubida } \\
\text { T. protracta } \\
\text { T. gerstaeckeri } \\
\text { T. indictiva } \\
\text { T. neotomae } \\
\text { T. recurva }\end{array}$ & $\begin{array}{l}\text { T. leticularia } \\
\text { T. sanguisuga } \\
\text { T. rubrofasciata }\end{array}$ & None \\
\hline Medicaid expansion? [45] & Adopted & Not adopted & Not adopted & Adopted \\
\hline $\begin{array}{l}\% \text { uninsured Henry J. Kaiser Family } \\
\text { Foundation 2018b [83] }\end{array}$ & 8 & 15 & 12 & 6 \\
\hline Patients treated [46] & 111 & 40 & 15 & 35 \\
\hline Key epidemiological studies & $\begin{array}{l}\text { Meymandi et al. } \\
2017 \text { [47] }\end{array}$ & $\begin{array}{l}\text { Garcia et al. } \\
2015[6]\end{array}$ & $\begin{array}{l}\text { Leiby et al. } \\
2002[48]\end{array}$ & $\begin{array}{l}\text { Kapelusznik et al. } \\
2013[49]\end{array}$ \\
\hline
\end{tabular}

\section{California}

In California, a large-scale screening program coordinated by the Center of Excellence for Chagas Disease at Olive View-UCLA Medical Center (CECD) found a CD prevalence of $1.24 \%$ among 4755 Latin American-born residents of Los Angeles [47]. The CECD observed an even higher prevalence $(7.4 \%)$ in a sample of close relatives of previously diagnosed patients [54]. Further, the CECD identified a hidden burden of the disease among Latin American-born patients with nonischemic cardiomyopathy, pacemakers, and electrocardiogram abnormalities [55-57]. These studies suggest a significant impact of $\mathrm{CD}$ in Los Angeles, where up to 30,000 people may be affected.

\section{Local Transmission Dynamics}

Other research suggests limited autochthonous transmission also takes place in California. The first California case of vector transmission was reported in 1982 [58]. Autochthonous transmission was thought to be rare, but the national implementation of blood donation screening in 2007 has uncovered cases of CD that cannot be explained by other factors, such as residence or travel in Latin America. Since then, blood donor screening identified a probable case of vector transmission in the greater
Los Angeles area [7]. Furthermore, research suggests triatomines as well as $T$. cruzi are commonly encountered in the natural environment, even near urban areas. Studies of T. protracta in southern California have found $T$. cruzi infection rates from 19 to $36 \%$, while the rate was $55 \%$ in a sample from northern California $[59,60]$. Other research indicated $20 \%$ of residents in Los Angeles's eastern suburbs had observed triatomines in their neighborhood, and $5 \%$ even collected triatomine samples for the researchers [61].

\section{Access to Treatment}

CECD research highlights access challenges for people with $\mathrm{CD}$ in southern California [37, 62]. Los Angeles is home to 2.5 million Latin American-born residents; $79 \%$ are from Mexico and 12\% from El Salvador [63]. Both in their home countries and in the USA, this population has had almost no exposure to health education campaigns or media messages about CD. A survey of 2677 Latin American residents of Los Angeles found $86 \%$ had never heard of CD, yet the majority recalled seeing triatomines, while $79 \%$ indicated they had lived or stayed in a home at least partly constructed of adobe (a known risk factor for CD transmission) while in Latin America [62]. This lack of exposure to information on CD keeps the disease hidden and suppresses demand for screening. 
An even more concerning issue is limited awareness of the disease among health care providers. Los Angeles CD patients who test positive after donating blood often report their physicians are unfamiliar with $C D$, which poses a significant barrier to commencing treatment [37]. Positive donors in Los Angeles County receive contact information for the CECD, but in other parts of the state, patients may face extreme challenges in finding a provider prepared to offer treatment. The CECD has treated patients from as far away as Sacramento.

Several California counties offer basic health insurance options to cover people who would not otherwise be able to obtain coverage. This has had a positive impact in enabling low-income patients in Los Angeles to begin treatment. Nonetheless, some of these programs have reported significant declines in enrollment since 2017, as immigrants have felt heightened concerns that enrolling in such programs will entail negative repercussions for themselves or family members. In one local county-sponsored program, $23 \%$ of participants actually discontinued their insurance coverage in 2017, although it is unknown how many of those who unenrolled were Latinos [52]. Moreover, patients who are privately insured sometimes report significant delays in obtaining authorization of coverage for treatment, simply because insurers may not be familiar with CD. Even if patients incur no costs for treatment, other significant barriers must be considered. A qualitative study with 50 CECD patients found that the majority lived below the poverty line; lack of transportation and time off from work (either to go to appointments or to manage side effects from antitrypanosomal drugs) were cited as major impediments to health care access [37].

\section{Texas}

In 2013, CD became a reportable condition in Texas. As a result, between 2013 and 2016, a total of 91 cases were confirmed by the Texas Department of State Health Services (TxDSHS). Of those cases, 67\% were imported, $22 \%$ were local transmissions, and $11 \%$ had unknown transmission sources [64]. A recent study of blood bank data from Texas estimated a statewide CD prevalence of one per 6500 Texans [65]. Although there have been few large-scale screening programs conducted in Texas, there have been significant efforts to create collaborative partnerships to increase vector surveillance and risk communication on the disease. The Texas Chagas Task Force was created in 2015 through CDC funding. The Task Force, consisting of researchers, public health agencies, entomologists, veterinarians, and health care providers in both military and civilian communities, represents a collaborative effort to raise awareness of $\mathrm{CD}$ and create a statewide network to support improved screening and treatment.

\section{Local Transmission Dynamics}

Reports of triatomine activity in Texas date back to as early as the 1930s [60]. The first autochthonous transmission of CD in Texas was documented in 1955 in a 10month-old girl from Corpus Christi [66]. Due to environmental factors and vector prevalence, local transmission occurs in Texas. Multiple studies have consistently shown over $60 \%$ prevalence of $T$. cruzi infection in local triatomines [67, 68]. At least eight different species of triatomes have been found in Texas; the four major species are Triatoma gerstaeckeri, Triatoma indictiva, Triatoma sanguisuga, and Triatoma protracta woodi. In several studies on infected vectors, blood meals from multiple mammalian hosts have been found, particularly dogs, suggesting a higher risk for domestic transmission cycles in Texas [6]. In a 2013 study, shelter dogs across seven ecologic regions in Texas were tested and found to have a statewide average seroprevalence of $8.8 \%$ [69]. CD was a reportable condition in animals between 2013 and 2015, with 439 reports of canine CD during that time [64]. CD in animals is no longer a reportable condition, possibly due to limited resources to handle the large inflow of reports. Although there is sufficient evidence supporting autochthonous transmission potential in Texas and limited evidence to show it is occurring [59], there is still relatively little screening in human populations.

\section{Access to Treatment}

There has been only limited research on access to treatment for people with CD in Texas since there are currently no largescale screening or treatment programs in place. Baylor College of Medicine has been actively engaged in research projects to screen and treat CD patients in Harris County, Texas; however, funding constraints make it challenging to provide consistent, adequate screening coverage to all at-risk populations.

Large gaps in insurance coverage and high rates of noncoverage make it a challenge for Texans to access screening and treatment for CD. The Texas Chagas Task Force has worked closely with health care provider networks across the state to elevate awareness of CD, but it often confronts the problem of physicians not having the capacity to screen uninsured individuals. On multiple occasions, low-cost or free clinics (including Federally Qualified Health Clinics) were targeted for outreach due to their patient base being at a higher risk for undiagnosed CD. The majority of these clinics stated that they were unable to support a screening program due to the costs 
of testing, intensive management resources needed for treatment if a positive case is found, and the belief that prevalence was not high enough to warrant the allocation of valuable resources.

Another concern is low provider awareness. People have repeatedly contacted the Task Force requesting support after their provider told them that the letter they received from the blood bank with a positive result for CD was not concerning because (1) CD is not present in the USA and/or (2) it is probably a false positive result and nothing further needs to be done [53]. However, in a recent mixedmethods study looking at CD knowledge, attitudes, and practices among Texas providers, the majority believed that $\mathrm{CD}$ is under-diagnosed in Texas. Also, when given a short questionnaire on general knowledge regarding $\mathrm{CD}$ and protocols for treatment, the average score was 52 out of 100 [70]. Infectious disease specialists had the highest level of awareness; the most frequently incorrect questions across practices pertained to treatment options. Qualitative results indicated that infectious disease specialists were mainly concerned with screening and access to drugs for treatment, while cardiologists were more concerned with language barriers and quality of the diagnostics. This study illustrates the need for a common screening, diagnostic, and treatment protocol for physicians that can be easily accessed, with greater transparency in diagnostic research to help physicians improve their practices.

\section{Vector Identification}

The general public and providers have reported several other anecdotal stories through the Task Force regarding a general lack of knowledge of the vectors. In Texas, there are a variety of "look-alike" species that are often confused for triatomines. This confusion has led to wasted time and resources along with unnecessary alarm in people regarding a possible exposure. In 2018, the Task Force produced a publication called "The Kissing Bug and Chagas Disease Guide: What You Need to Know" that is aimed at a general audience in locations where there is potential for local or imported transmission [71]. This guide and similar materials can also serve as communication tools for physicians to discuss risks with their patients. It is hoped that with increased proper identification of the vector and improved knowledge among providers, more testing will occur and help improve understanding of the prevalence in the USA.

\section{Impact on a Texas US Military Installation}

The US military has been a primary and active partner in the development of the Texas Chagas Task Force and is aware of current and potential risks to service members
(SMs), both domestically and abroad. Surveillance of CD with the military first came about as a result of multiple military working dogs (MWDs) requiring medical attention attributable to cardiomyopathy, later diagnosed as CD. A study was then conducted to assess seroprevalance in MWDs, which was $8 \%$ among the MWDs housed and trained at Joint Base San Antonio (JBSA-Lackland) in San Antonio, Texas [72, 73]. Unpublished data from another study conducted on the same military base found that $57 \%(n=75)$ of 131 triatomines collected were T. cruzi-positive, with $33 \%(n=25)$ testing positive for human blood [74]. These data prompted the initiation of new administrative, technical, and personal protective measures to protect SMs and MWDs against exposure during field training exercises at JBSA-Lackland. Additionally, this information also prompted an ongoing voluntary screening study at JBSA-Lackland to test basic military trainees (BMTs) at the beginning and end of their training sessions at the installation. This screening program, however, was implemented after protective measures were put into place, and there have not been any cases of transmission occurring on JBSA-Lackland to date [73]. It has been recommended that additional vector surveillance and testing for $\mathrm{CD}$ be conducted on military training installations throughout the southern USA in an effort to surveil training environments that may present hazardous exposure to our military populations. There are currently inconsistent policies and protocols across the armed services on how to address positive cases when discovered among SMs, leading to possible discharging of personnel when they are found to be positive. Additionally, military physicians face similar barriers to those facing civilian populations, including low awareness of the disease [75].

\section{Florida}

Although autochthonous transmission has not been documented in Florida, one study found that $54 \%$ of raccoons and $52 \%$ of opossums collected from Florida were seropositive [76]. A survey of 181,139 Miami-area blood donors from 1994 to 1998 found a seropositive rate of 1 in 9000, which is over three times higher than the national average $[5,48]$. Although there have not been further epidemiological studies, AABB data indicate that most seropositive donors are clustered in Southeast Florida in the Miami-Fort Lauderdale corridor, with another cluster in Central Florida. Moreover, probable congenital transmission has been reported in Miami (the patients, two brothers born in the USA to a Bolivian mother, had grown to adulthood, but other transmission routes were ruled out) [77]. The population at risk for $\mathrm{CD}$ in Florida differs substantially from at- 
Table 2 Actions needed to strengthen health systems to scale up diagnosis and treatment of CD in the USA

\begin{tabular}{|c|c|}
\hline Barrier & Actions needed \\
\hline $\begin{array}{l}\text { Limited knowledge of disease } \\
\text { burden. }\end{array}$ & $\begin{array}{l}\text { Studies to better understand the burden of the disease in both urban and } \\
\text { rural areas of the southern USA, along with the incidence of } \\
\text { autochthonous transmission among higher risk populations. }\end{array}$ \\
\hline Few providers offering treatment. & $\begin{array}{l}\text { Development of a statewide and/or national network of providers capable } \\
\text { of offering treatment, along with a website where people can quickly } \\
\text { identify nearby providers for testing and treatment. }\end{array}$ \\
\hline Low provider awareness. & $\begin{array}{l}\text { Increased health education measures and protocols for providers and } \\
\text { greater incorporation of CD diagnosis and treatment in state medical } \\
\text { schools. }\end{array}$ \\
\hline Low patient awareness. & $\begin{array}{l}\text { Public education program to raise awareness, especially among the Latin } \\
\text { American-born population, and to stimulate demand for testing. }\end{array}$ \\
\hline Absence of screening programs. & $\begin{array}{l}\text { Routine screening program, ideally through primary care clinics, } \\
\text { throughout the states identified as having the most-at-risk populations. }\end{array}$ \\
\hline $\begin{array}{l}\text { Limitations in current diagnostic } \\
\text { capabilities. }\end{array}$ & $\begin{array}{l}\text { Identification of a testing algorithm with high sensitivity and specificity } \\
\text { for identifying patients infected with T. cruzi strains present in the } \\
\text { southern USA, Mexico, and Central America. }\end{array}$ \\
\hline $\begin{array}{l}\text { Access challenges for vulnerable } \\
\text { at-risk populations. }\end{array}$ & $\begin{array}{l}\text { Use of mobile clinics or telemedicine to help screen and treat people in } \\
\text { rural areas. }\end{array}$ \\
\hline
\end{tabular}

risk populations in California and Texas; Cubans and Puerto Ricans, who make up much of Florida's Latino population, are not at high risk for CD. In contrast to California and Texas, Mexico and Colombia are the most common endemic countries of origin, accounting for about $13 \%$ of Florida's immigrant population [78].

\section{New York}

An analysis of blood donors in the New York metropolitan area from 2007 to 2009 showed that there were 70 seropositive individuals and an overall state prevalence of $0.0083 \%$; among donors self-identified as Hispanic/Latino, there were 52 seropositive individuals and a $0.052 \%$ prevalence. There was a cluster of positive results in eastern Long Island [79]. In another state-level study from 2007 to 2011 of over one million donors, 204 donors were positive on enzyme-linked immunosorbent assay, 77 of whom were confirmed positive by radioimmunoprecipitation assay. The study showed that 29 of the seropositive individuals had donated blood prior to the implementation of screening of the blood supply, and 2 likely cases of transfusion transmission were identified [80]. However, like Los Angeles, New York appears to have a hidden burden of Chagas cardiomyopathy. A hospital-based study found that 5 of 39 (13\%) Latin America-born patients with nonischemic cardiomyopathy were positive for T. cruzi [49], highlighting the value of targeted surveillance in this state's high-risk patient population. New York's Latin America-born population is also unique; the largest country of origin, the Dominican Republic, is considered non- endemic. However, about $10 \%$ of New York's immigrants come from two endemic countries: Mexico and Ecuador [81].

\section{Conclusion}

Numerous interrelated barriers prevent over $99 \%$ of CD patients in the USA from accessing diagnosis and treatment. These barriers include not only limitations in the currently available drugs and diagnostics, but also substantial gaps in epidemiological surveillance, limited awareness among providers and patients, and limited information resources for the public. While states share these challenges, contexts differ significantly in terms of transmission dynamics, affected populations, and health system resources. Table 2 highlights key actions needed to overcome major barriers in all states. While the Texas Chagas Task Force and CECD have begun to confront these issues on a small scale, more resources and a broad response from the public health system are urgently needed, with the goal of assuring systematic screening programs and wider availability of treatment in primary health care. Such screening programs will depend on diagnostic tools and procedures capable of accurately detecting infection in the diverse range of the US population affected by CD. Screening of CD is cost-effective [82] and benefits society by reducing the heavy burden of the disease. Importantly, resources should be available to help newly diagnosed patients cope with concern and anxiety surrounding CD. Finally, while CD affects all sectors of society, it is most prevalent among vulnerable groups 
whose access to health care should be affirmed and carefully safeguarded.

\section{Compliance with Ethical Standards}

Conflict of Interest Colin J. Forsyth, Paula Stigler Granados, Gerardo J. Pacheco, José A. Betancourt, and Sheba K. Meymandi declare no conflict of interest. Colin Forsyth earned a salary from the Drugs for Neglected Diseases initiative and Médecins sans Frontières/Doctors without Borders USA while working on this article.

Human and Animal Rights and Informed Consent This article does not contain any studies with human or animal subjects performed by any of the authors.

Open Access This article is distributed under the terms of the Creative Commons Attribution 4.0 International License (http:// creativecommons.org/licenses/by/4.0/), which permits unrestricted use, distribution, and reproduction in any medium, provided you give appropriate credit to the original author(s) and the source, provide a link to the Creative Commons license, and indicate if changes were made.

Publisher's Note Springer Nature remains neutral with regard to jurisdictional claims in published maps and institutional affiliations.

\section{References}

Papers of particular interest, published recently, have been highlighted as:

- Of importance

•. Of major importance

1. World Health Organization. Global health estimates 2016: disease burden by cause, age, sex, by country and by region, 2000-2016. Geneva. 2018.

2. Lee BY, Bacon KM, Bottazzi ME, Hotez PJ. Global economic burden of Chagas disease: a computational simulation model. Lancet Infect Dis. 2013;13(4):342-8. https://doi.org/10.1016/ S1473-3099(13)70002-1.

3. Howard E, Xiong X, Carlier Y, Sosa-Estani S, Buekens P. Frequency of the congenital transmission of Trypanosoma cruzi: a systematic review and meta-analysis. BJOG. 2014;121(1):22-33. https://doi.org/10.1111/1471-0528.12396.

4. Klotz SA, Dorn PL, Mosbacher M, Schmidt JO. Kissing bugs in the United States: risk for vector-borne disease in humans. Environ Health Insights. 2014;8(Suppl 2):49-59. https://doi.org/10.4137/ EHI.S16003.

5. Cantey PT, Stramer SL, Townsend RL, Kamel H, Ofafa K, Todd CW, et al. The United States Trypanosoma cruzi Infection Study: evidence for vector-borne transmission of the parasite that causes Chagas disease among United States blood donors. Transfusion. 2012;52(9):1922-30. https://doi.org/10.1111/j.1537-2995.2012. 03581.x.

6. Garcia MN, Aguilar D, Gorchakov R, Rossmann SN, Montgomery SP, Rivera $\mathrm{H}$, et al. Evidence of autochthonous Chagas disease in southeastern Texas. Am J Trop Med Hyg. 2015;92(2):325-30. https://doi.org/10.4269/ajtmh.14-0238.

7. Hernandez S, Flores CA, Viana GM, Sanchez DR, Traina MI, Meymandi SK. Autochthonous transmission of Trypanosoma cruzi in southern California. Open Forum Infect Dis. 2016;3(4):ofw227. https://doi.org/10.1093/ofid/ofw227.

8. Klotz SA, Dorn PL, Klotz JH, Pinnas JL, Weirauch C, Kurtz JR, et al. Feeding behavior of triatomines from the southwestern United States: an update on potential risk for transmission of Chagas disease. Acta Trop. 2009;111(2):114-8. https://doi.org/10.1016/j. actatropica.2009.03.003.

9. Bern C, Montgomery SP. An estimate of the burden of Chagas disease in the United States. Clin Infect Dis. 2009;49(5):e52-e4. https://doi.org/10.1086/605091.

10.• Manne-Goehler J, Reich MR, Wirtz VJ. Access to care for Chagas disease in the United States: a health systems analysis. Am J Trop Med Hyg. 2015;93(1):108-13. https://doi.org/10.4269/ajtmh.140826. A mixed methods study looking at the estimated burden of Chagas disease in the US and analyzing trends in access to care for this neglected disease. It presents an important look at barriers to access to care, which includes low provider awareness and limited diagnostics. This study is important in that it shows a need for including a health systems perspective when scaling up access to treatment for Chagas and makes recommendations on this approach.

11. Manne JM, Snively CS, Ramsey JM, Salgado MO, Barnighausen T, Reich MR. Barriers to treatment access for Chagas disease in Mexico. PLoS Negl Trop Dis. 2013;7(10):e2488. https://doi.org/ 10.1371/journal.pntd.0002488.

12. Cucunuba ZM, Manne-Goehler JM, Diaz D, Nouvellet P, Bernal O, Marchiol A, et al. How universal is coverage and access to diagnosis and treatment for Chagas disease in Colombia? A health systems analysis. Soc Sci Med (1982). 2017;175:187-98. https://doi.org/10. 1016/j.socscimed.2017.01.002.

13. Basile L, Jansa JM, Carlier Y, Salamanca DD, Angheben A, Bartoloni A, et al. Chagas disease in European countries: the challenge of a surveillance system. Euro Surveill. 2011;16(37).

14. Alonso-Vega C, Billot C, Torrico F. Achievements and challenges upon the implementation of a program for national control of congenital Chagas in Bolivia: results 2004-2009. PLoS Negl Trop Dis. 2013;7(7):e2304. https://doi.org/10.1371/journal.pntd.0002304.

15. Barclay CA, Cerisola JA. Aspectos farmacológicos e resultados terapéuticos do benzonidazol novo agente quimioterapico para tratamiento da infeccao de Chagas. Prensa Med Argent. 1978;65: 239-44.

16. Sosa-Estani S, Segura EL, Ruiz AM, Velazquez E, Porcel BM, Yampotis C. Efficacy of chemotherapy with benznidazole in children in the indeterminate phase of Chagas' disease. Am J Trop Med Hyg. 1998;59(4):526-9.

17. Viotti R, Vigliano C, Lococo B, Bertocchi G, Petti M, Alvarez MG, et al. Long-term cardiac outcomes of treating chronic Chagas disease with benznidazole versus no treatment: a nonrandomized trial. Ann Intern Med. 2006;144(10):724-34.

18. Fabbro DL, Streiger ML, Arias ED, Bizai ML, del Barco M, Amicone NA. Trypanocide treatment among adults with chronic Chagas disease living in Santa Fe city (Argentina), over a mean follow-up of 21 years: parasitological, serological and clinical evolution. Rev Soc Bras Med Trop. 2007;40(1):1-10.

19. Cardoso CS, Ribeiro ALP, Oliveira CDL, Oliveira LC, Ferreira AM, Bierrenbach AL, et al. Beneficial effects of benznidazole in Chagas disease: NIH SaMi-Trop cohort study. PLoS Negl Trop Dis. 2018;12(11):e0006814. https://doi.org/10.1371/journal.pntd. 0006814.

20. Fabbro DL, Danesi E, Olivera V, Codebo MO, Denner S, Heredia $\mathrm{C}$, et al. Trypanocide treatment of women infected with Trypanosoma cruzi and its effect on preventing congenital Chagas. PLoS Negl Trop Dis. 2014;8(11):e3312. https://doi.org/ 10.1371/journal.pntd.0003312.

21. Sosa-Estani S, Cura E, Velazquez E, Yampotis C, Segura EL. Etiological treatment of young women infected with 
Trypanosoma cruzi, and prevention of congenital transmission. Rev Soc Bras Med Trop. 2009;42(5):484-7.

22. Morillo CA, Marin-Neto JA, Avezum A, Sosa-Estani S, Rassi AJ, Rosas F, et al. Randomized trial of benznidazole for chronic Chagas' cardiomyopathy. N Engl J Med. 2015;373(14):1295306. https://doi.org/10.1056/NEJMoa1507574.

23. Pecoul B, Batista C, Stobbaerts E, Ribeiro I, Vilasanjuan R, Gascon J, et al. The BENEFIT trial: where do we go from here? PLoS Negl Trop Dis. 2016;10(2):e0004343. https://doi.org/10.1371/journal. pntd.0004343.

24. FDA approves first U.S. treatment for Chagas disease. U.S. Food and Drug Administration. 2017.

25. Miller DA, Hernandez S, Rodriguez De Armas L, Eells SJ, Traina MM, Miller LG, et al. Tolerance of benznidazole in a United States Chagas disease clinic. Clin Infect Dis. 2015;60(8):1237-40. https:// doi.org/10.1093/cid/civ005.

26. Forsyth CJ, Hernandez S, Olmedo W, Abuhamidah A, Traina MI, Sanchez DR, et al. Safety profile of nifurtimox for treatment of Chagas disease in the United States. Clin Infect Dis. 2016;63(8): 1056-62. https://doi.org/10.1093/cid/ciw477.

27. Hernandez S, Forsyth C, Flores A, Lemus O, Marquez G, Sermeno $\mathrm{C}$ et al. Impact of daily dosage limits on frequency and severity of side effects in adult Chagas disease patients treated with benznidazole in a U.S. Clinic. American Society of Tropical medicine and Hygiene; November 8; Baltimore, MD. 2017.

28. Dias JCP, Ramos AN Jr, Gontijo ED, Luquetti A, Shikanai-Yasuda MA, Coura JR, et al. Second Brazilian consensus on Chagas disease, 2015. Rev Soc Bras Med Trop. 2016;49:3-60.

29. Meymandi S, Hernandez S, Park S, Sanchez DR, Forsyth C. Treatment of Chagas disease in the United States. Curr Treat Options Infect Dis. 2018;10(3):373-88. https://doi.org/10.1007/ s40506-018-0170-z. The authors describe recommendations for screening and treating Chagas patients in the US. They provide a list of potential higher risk patients to consider for screening and discuss important aspects of diagnosis and treatment protocols within a US context. This is an important guideline for clinical care and treatment of Chagas patients in the US.

30. Montgomery SP, Starr MC, Cantey PT, Edwards MS, Meymandi SK. Neglected parasitic infections in the United States: Chagas disease. Am J Trop Med Hyg. 2014;90(5):814-8. https://doi.org/ 10.4269/ajtmh. 13-0726.

31. Use of serological tests to reduce the risk of transmission of Trypanosoma cruzi infection in blood and blood components: guidance for industry. Silver Spring: Food and Drug Administration, Center for Biologics Evaluation and Research. 2017.

32. Edwards MS, Abanyie FA, Montgomery SP. Survey of pediatric infectious diseases society members about congenital chagas disease. Pediatr Infect Dis J. 2018;37(1):e24-e7. https://doi.org/10. 1097/inf.0000000000001733.

33. Verani JR, Montgomery SP, Schulkin J, Anderson B, Jones JL. Survey of obstetrician-gynecologists in the United States about Chagas disease. Am J Trop Med Hyg. 2010;83(4):891-5. https:// doi.org/10.4269/ajtmh.2010.09-0543.

34. Stimpert KK, Montgomery SP. Physician awareness of Chagas disease, USA. Emerg Infect Dis. 2010;16(5):871-2. https://doi.org/10. 3201/eid1605.091440.

35. Forsyth CJ, Hernandez S, Flores CA, Roman MF, Nieto JM, Marquez $\mathrm{G}$ et al. Sociocultural factors and access to treatment for Chagas disease in the United States. American Society of Tropical Medicine and Hygiene; November 16; Atlanta, GA. 2016.

36. personal communication. In: Stigler Granados P, editor. Conversation at Texas Chagas Task Force Meeting (teleconference). ed. 2018

37. Forsyth CJ, Hernandez S, Flores CA, Roman MF, Nieto JM, Marquez G, et al. "It's Like a Phantom Disease": patient perspectives on access to treatment for Chagas disease in the United States. Am J Trop Med Hyg. 2018;98(3):735-41. https:// doi.org/10.4269/ajtmh.17-0691.

38. Forsyth C. Controlled but not cured: structural processes and explanatory models of Chagas disease in tropical Bolivia. Soc Sci Med (1982). 2015;145:7-16. https://doi.org/10.1016/j.socscimed. 2015.09.022.

39. Magnani C, Dias JC, Gontijo ED. How health activities view man and how man rethinks them: an anthropological analysis of Chagas disease control. Cad Saude Publica. 2009;25(9):1947-56.

40. Ozaki Y, Guariento ME, de Almeida EA. Quality of life and depressive symptoms in Chagas disease patients. Qual Life Res. 2011;20(1):133-8. https://doi.org/10.1007/s11136-010-9726-1.

41. Forsyth CJ. "I Cannot Be Worried": living with Chagas disease in tropical Bolivia. PLoS Negl Trop Dis. 2017;11(1):e0005251. https://doi.org/10.1371/journal.pntd.0005251.

42. Manne-Goehler J, Umeh CA, Montgomery SP, Wirtz VJ. Estimating the burden of Chagas disease in the United States. PLoS Neg Trop Dis. 2016;10(11):e0005033. https://doi.org/10. 1371/journal.pntd.0005033. The authors calculated estimates of the prevalence of Chagas disease in the US and then describe the estimation for each state. The state level results showed that four states (California, Texas, Florida and New York) have over 10,000 estimated cases and several others have greater than 5,000 cases. The study is important in that it reflects the estimated distribution of Chagas disease in the US and provides guidance on future surveillance and interventions.

43. Flores A. How the U.S. Hispanic population is changing: Pew Research Center. 2017 September 18.

44. Henry J. Kaiser Family Foundation. Status of State Action on the Medicaid Expansion Decision 2018.

45. Henry J. Kaiser Family Foundation. Health Insurance Coverage of the Total Population. 2018.

46. Herwaldt B, Dougherty C, Allen C, Jolly J, Brown M, Yu P, et al. Characteristics of patients for whom benznidazole was released through the CDC-sponsored investigational new drug program for treatment of Chagas disease - United States, 2011-2018. MMWR. 2018;67(29):803-5.

47. Meymandi SK, Forsyth CJ, Soverow J, Hernandez S, Sanchez D, Montgomery S, et al. Prevalence of Chagas disease in the Latin American-born population of Los Angeles. Clin Infect Dis. 2017;64(9):1182-8.

48. Murillo J, Bofill LM, Bolivar H, Torres-Viera C, Urbina JA, Benhayon D, et al. Congenital Chagas' disease transmission in the United States: diagnosis in adulthood. IDCases. 2016;5:72-5. https://doi.org/10.1016/j.idcr.2016.07.011.

49. Immigrants in New York. American Immigration Council. 2017. Washington, DC: October 4, 2017. https://www. americanimmigrationcouncil.org/research/immigrants-in-newyork. Accessed 5 Oct 2018.

50. Bennett C, Straily A, Haselow D, Weinstein S, Taffner R, Yaglom $\mathrm{H}$, et al. Chagas disease surveillance activities - seven states, 2017. MMWR Morb Mortal Wkly Rep. 2018;67:738-41.

51. Henry J. Jaiser Family Foundation. Health Coverage \& Uninsured. In: State Health Facts. 2018. https://www.kff.org/state-category/ health-coverage-uninsured/. Accessed 31 Dec 2018.

52. Kennedy K. Hispanics forgo health services to avoid officials' attention, advocates say. The Washington Post 2018 January 21.

53. Stigler Granados P. Chagas disease: the Silent Killer American Public Health Association Annual Meeting; November 10-14; San Diego, CA. 2018.

54. Hernandez S, Forsyth C, Flores CA, Meymandi SK. Prevalence of Chagas disease among relatives of positive cases in Los Angeles, California. American College of Cardiology 66th Annual Scientific Session and Expo. 2017 March 17-19; Washington, DC. 
55. Traina MI, Sanchez DR, Hernandez S, Bradfield JS, Labedi MR, Ngab TA, et al. Prevalence and Impact of Chagas disease among Latin American immigrants with nonischemic cardiomyopathy in Los Angeles, California. Circ Heart fail. 2015;8(5):938-43. https:// doi.org/10.1161/circheartfailure.115.002229.

56. Park S, Sanchez DR, Traina MI, Bradfield JS, Hernandez S, Ufion AJA, et al. The prevalence of Chagas disease among Latin American immigrants with pacemakers in Los Angeles, California. Am J Trop Med Hyg. 2017;96(5):1139-42. https://doi. org/10.4269/ajtmh.16-0826.

57. Traina MI, Hernandez S, Sanchez DR, Dufani J, Salih M, Abuhamidah AM, et al. Prevalence of Chagas disease in a U.S. population of Latin American immigrants with conduction abnormalities on electrocardiogram. PLoS Negl Trop Dis. 2017;11(1): e0005244. https://doi.org/10.1371/journal.pntd.0005244.

58. Navin TR, Roberto RR, Juranek DD, Limpakarnjanarat K, Mortenson EW, Clover JR, et al. Human and sylvatic Trypanosoma cruzi infection in California. Am J Public Health. 1985;75(4):366-9.

59. Hwang WS, Zhang G, Maslov D, Weirauch C. Infection rates of Triatoma protracta (Uhler) with Trypanosoma cruzi in Southern California and molecular identification of trypanosomes. Am J Trop Med Hyg. 2010;83(5):1020-2. https://doi.org/10.4269/ ajtmh.2010.10-0167.

60. Shender LA, Lewis MD, Rejmanek D, Mazet JAK. Molecular diversity of Trypanosoma cruzi detected in the vector Triatoma protracta from California, USA. PLOS Negl Trop Dis. 2016;10(1):e0004291. https://doi.org/10.1371/journal.pntd. 0004291.

61. Walter J, Fletcher E, Moussaoui R, Gandhi K, Weirauch C. Do bites of kissing bugs cause unexplained allergies? Results from a survey in triatomine-exposed and unexposed areas in Southern California. PLoS One. 2012;7(8):e44016. https://doi.org/10.1371/journal. pone.0044016.

62. Sanchez DR, Traina MI, Hernandez S, Smer AM, Khamag H, Meymandi SK. Chagas disease awareness among Latin American immigrants living in Los Angeles, California. Am J Trop Med Hyg. 2014;91(5):915-9. https://doi.org/10.4269/ajtmh.14-0305.

63. Pew Research Center. Hispanic population in select U.S. metropolitan areas, 2011.

64. Texas Department of State Health Services. Chagas Disease Data. https://www.dshs.texas.gov/idcu/disease/chagas/data. Accessed 6 Nov 2018.

65. Garcia MN, Woc-Colburn L, Rossmann SN, Townsend RL, Stramer SL, Bravo M, et al. Trypanosoma cruzi screening in Texas blood donors, 2008-2012. Epidemiol Infect. 2016;144(5): 1010-3. https://doi.org/10.1017/s0950268814002234.

66. Garcia MN, Woc-Colburn L, Aguilar D, Hotez PJ, Murray KO. Historical perspectives on the epidemiology of human Chagas disease in Texas and recommendations for enhanced understanding of clinical Chagas disease in the southern United States. PLoS Negl Trop Dis. 2015;9(11):e0003981. https://doi.org/10.1371/journal. pntd.0003981. The authors present an important historical perspective of the disease burden and presence of Chagas disease in Texas. The paper shows that Chagas disease does in fact have a longer history in the US and is not necessarily a new or emerging disease. It is important to understand Chagas disease history in the US in order to further advance how we approach epidemiological investigations and prioritize interventions and policy.

67. Gorchakov R, Trosclair LP, Wozniak EJ, Feria PT, Garcia MN, Gunter SM, et al. Trypanosoma cruzi infection prevalence and bloodmeal analysis in triatomine vectors of Chagas disease from rural peridomestic locations in Texas, 2013-2014. J Med Entomol. 2016;53(4):911-8. https://doi.org/10.1093/jme/tjw040.

68. Wozniak EJ, Lawrence G, Gorchakov R, Alamgir H, Dotson E, Sissel B, et al. The biology of the triatomine bugs native to south Central Texas and assessment of the risk they pose for autochthonous Chagas disease exposure. J Parasitol. 2015;101(5):520-8. https://doi.org/10.1645/15-748.

69. Tenney TD, Curtis-Robles R, Snowden KF, Hamer SA. Shelter dogs as sentinels for Trypanosoma cruzi transmission across Texas. Emerg Infect Dis. 2014;20(8):1323-6. https://doi.org/10. 3201/eid2008.131843.

70. Pacheco J. Chagas disease knowledge, attitudes and practices among Texas physicians. [Unpublished dissertation]. In press. 2018.

71. Stigler Granados P, Hamer SA, Hamer G, Montgomery SP, Stimpert KK, Mayes BC et al. Kissing bugs and Chagas disease: what you need to know. University of Texas Health, San Antonio, and Texas A\&M University: Texas Chagas Taskforce. 2018.

72. McPhatter L, Roachell W, Mahmood F, Hoffman L, Lockwood N, Osuna A, et al. Vector surveillance to determine species composition and occurrence of Trypanosoma cruzi at three military installations in San Antonio, Texas. US Army Med Dep J. 2012:12-21.

73. Webber BJ, Pawlak MT, Valtier S, Daniels CC, Tully CC, Wozniak EJ, et al. Prevalence and seroprevalence of Trypanosoma cruzi infection in a military population in Texas. Am J Trop Med Hyg. 2017;97(5):1477-81. https://doi.org/10.4269/ajtmh.17-0109.

74. Daniels C, Harris N, Woc-Colburn L, Gunter SM, Gorchakov R, Murray KO, et al. Autochthonous Chagas disease in the southern United States: a case report of suspected residential and military exposures. Zoonoses Public Health. 2017;64(6):491-3. https://doi. org/10.1111/zph.12360.

75. Brown EL, Roellig DM, Gompper ME, Monello RJ, Wenning KM, Gabriel MW, et al. Seroprevalence of Trypanosoma cruzi among eleven potential reservoir species from six states across the southern United States. Vector Borne Zoonotic Dis. 2010;10(8):757-63. https://doi.org/10.1089/vbz.2009.0009.

76. Leiby DA, Herron RM Jr, Read EJ, Lenes BA, Stumpf RJ. Trypanosoma cruzi in Los Angeles and Miami blood donors: impact of evolving donor demographics on seroprevalence and implications for transfusion transmission. Transfusion. 2002;42(5):549_ 55.

77. Zaniello BA, Kessler DA, Vine KM, Grima KM, Weisenberg SA. Seroprevalence of Chagas Infection in the donor population. PLoS Negl Trop Dis. 2012;6(7):e1771. https://doi.org/10.1371/journal. pntd.0001771.

78. Fact Sheet: Immigrants in Florida. American Immigration Council. 2017. Washington, DC: October 4, 2017. https://www. americanimmigrationcouncil.org/research/immigrants-florida. Accessed 5 Oct 2018.

79. Kessler DA, Shi PA, Avecilla ST, Shaz BH. Results of lookback for Chagas disease since the inception of donor screening at New York Blood Center. Transfusion. 2013;53(5):1083-7. https://doi.org/10. 1111/j.1537-2995.2012.03856.x.

80. Kapelusznik L, Varela D, Montgomery SP, Shah AN, Steurer FJ, Rubinstein D, et al. Chagas disease in Latin American immigrants with dilated cardiomyopathy in New York City. Clin Infect Dis. 2013;57(1):e7. https://doi.org/10.1093/cid/cit199.

81. Stillwaggon E, Perez-Zetune V, Bialek SR, Montgomery SP. Congenital Chagas disease in the United States: cost savings through maternal screening. Am J Trop Med Hyg. 2018;98(6): 1733-42. https://doi.org/10.4269/ajtmh.17-0818.

82. Pew Research Center. Demographic and Economic Profiles of Hispanics by State and County, 2014. Washington DC, 2016. http://www.pewhispanic.org/states. Accessed 25 Sep 2018. 